\title{
0 novo mainstream da música regional: axé, brega, reggae e forró eletrônico no Nordeste
}

Felipe Trotta e Márcio Monteiro

\section{Resumo}

Partindo de uma reflexão acerca da conceituação de música independente, este artigo busca caracterizar parte da produção musical do Nordeste brasileiro como um novo mainstream regional. Com circulação expressiva na região, a música de alguns gêneros como axé, brega, reggae e sobretudo o chamado forró eletrônico alcança índices de consagração comercial que ultrapassam estética e quantitativamente os limites da classificação independente. Assim, vê-se nestas práticas musicais um conjunto de valores e símbolos associados ao público jovem que, girando em torno das idéias de festa-amor-sexo consegue grande projeção no mercado musical.

\section{Palavras-chave}

Mercado de música. Música popular. Forró. Independentes.

Felipe Trotta | trotta.felipe@gmail.com

Doutor em Comunicação e Cultura pela Universidade Federal do Rio de Janeiro - UFRJ. Professor do Departamento de Comunicação Social da Universidade Federal de Pernambuco - UFPE - e do Programa de Pós-Graduação em Comunicação da UFPE.

\section{Márcio Monteiro | themarcmont@hotmail.com}

Mestrando do Programa de Pós-Graduação em Comunicação da UFPE.

\section{Introdução}

As novas configurações tecnológicas ligadas à produção e ao consumo de música têm produzido uma aguda complexificação no mercado musical. Se, por um lado, é possível constatar uma progressiva perda de valor da música gravada (HERSCHMANN, 2007), por outro, podemos notar que estratégias alternativas de distribuição de fonogramas têm obtido razoável êxito na diversificação de ofertas musicais disponíveis, potencializando um mercado de "nichos" que passa a competir com o mercado de "massa" (ANDERSON, 2006).

Esses "nichos" formam uma rede complexa de tendências e estilos musicais, dispersos em vários gêneros e regiões do planeta. Em virtude das facilidades tecnológicas promovidas pela digitalização, alcançam circulação mundial ou local, e tornam comercialmente viáveis universos culturais com públicos numericamente reduzidos. Nos debates sobre essa nova configuração mercadológica, pode-se perceber uma ênfase na abordagem de fenômenos musicais notadamente periféricos e de baixo grau de circulação que, 
de fato, têm demonstrado o alcance do novo mercado musical. Casos de bandas que obtiveram sucesso comercial a partir de estratégias de disponibilização gratuita de músicas na Internet (como Bonde do Role e Cansei de Ser Sexy) têm sido mencionados com freqüência nos diversos fóruns que discutem o fenômeno ${ }^{1}$. Outros, menos famosos, conseguem razoável projeção mercadológica e parecem continuamente atestar 0 grande potencial de democratização que a atual rede tecnológica tem possibilitado. Assim, a discussão sobre o novo mercado musical está intimamente ligada ao universo da chamada música "independente", termo vago 0 suficiente para abarcar artistas e grupos bastante diferentes esteticamente, unidos por uma certa posição periférica no mercado - seja como estratégia política consciente ou como contingência profissional.

No entanto, o que nos parece mais instigante ainda carente de discussão teórica apropriada - é precisamente a emergência de novos atores do mercado de música que estão ocupando não os espaços periféricos ou as "brechas" do mercado, mas posições hegemônicas na circulação musical. Bandas ligadas a determinados gêneros musicais no Norte e no Nordeste brasileiro têm conquistado determinados níveis de circulação que a antiga classificação de "independente" demonstra-se incapaz de absorver adequadamente sua extensão. Casos como o do forró cearense, do brega do Pará e do reggae no Maranhão são exemplos de um mercado de música movido a novas tecnologias que têm efetivamente alterado o alcance do próprio mainstream da música (historicamente protagonizado pelos grandes conglomerados internacionais). Alijadas de uma legitimidade estética avalizada pela crítica musical, essas músicas agregam dezenas de milhares de pessoas semanalmente, utilizando uma estrutura empresarial que dialoga com as esferas consagradas de difusão musical, como o rádio, mas que têm seu alcance amplificado através de um inusitado conjunto de dispositivos comerciais, substancialmente diferentes dos empregados pelos chamados independentes. Pode-se pensar aqui em um conjunto de práticas musicais cuja enorme penetração comercial em algumas regiões configura não apenas um segmento lucrativo desse mercado independente, mas um novo mainstream do mercado musical.

\section{Entre majors e indies}

A caracterização de um novo mainstream requer uma investigação mais cuidadosa do vocábulo e suas implicações estéticas e comerciais. Em primeiro lugar, devemos destacar que 0 termo

No último biênio pudemos participar de diversos encontros e debates sobre o mercado de música atual tais como os promovidos pela Feira da Música - Brasil, o Festival Coquetel Molotov, o Pré-Acorde Brasileiro e a Plataforma Integrada de Estudos Culturais (Festival de Inverno de Garanhuns), todos no estado de Pernambuco, além de diversos de fóruns na internet onde o tema aparece em destaque em lugares como o blog Overmundo e as listas de discussão da IASPM-LA (International Association of Study of Popular Music) e da Agenda do Samba-Choro, entre outros. 
- cuja tradução literal seria algo como "fluxo principal" - deriva do surgimento do que poderia ser chamado de um "contra-mainstream": a música "independente". Em ambos os casos, está em jogo aqui a conceituação de uma relação, isto é, um conjunto de posições e tomadas de posições pelos agentes de um determinado universo simbólico e profissional, negociando espaços privilegiados de prestígio e poder (BOURDIEU, 1989).

Durante todo o século XX, o "mercado de música" se confundiu com o mercado de "discos". Desde sua organização no início da década de 1900, as gravadoras sempre dispuseram de catálogos de discos com graus variados de vendagens. A circulação de músicas pela sociedade teve como principais protagonistas grandes empresas transnacionais do ramo do entretenimento, responsáveis pela maioria das ofertas de produtos musicais em todos os cantos do planeta. 0 mercado de música, então, passou a ser dividido comercialmente a partir dos números alcançados por cada artista e disco. Vendas mais expressivas representavam ambientes musicais, artistas e músicas com maior projeção e, conseqüentemente, mais importância econômica e comercial. No extremo oposto, discos com vendagem baixa, "encalhados" nas prateleiras e estoques, seriam classificados como "fracassos", implicando um julgamento de valor negativo sob o ponto de vista financeiro. Entre o sucesso e 0 fracasso de vendas, dezenas (ou centenas? Milhares?) de artistas ocuparam durante todo 0 século XX estágios intermediários de consagração comercial, estabelecendo um universo amplo de classificação baseado na quantidade de discos vendidos, que representou durante todas as décadas um índice seguro para classificar a popularidade de artistas, canções, discos e empresas no mercado.

Por outro lado, tal índice permitiu também o surgimento de estratégias de "resistência" desenvolvidas por atores situados em setores periféricos desse mercado aos modelos comerciais e estéticos das "grandes". É quando, por volta da década de 1970, surge o fenômeno dos artistas independentes, que se organizariam posteriormente em "gravadoras independentes", buscando comercializar seu repertório através da ocupação de espaços reduzidos de mercado, não contemplados pela música produzida nas grandes gravadoras.

De acordo com o Vocabulário de Música Pop, de Roy Shuker, o termo independente refere-se às gravadoras independentes, pequenos selos com relativa autonomia no processo produtivo e criativo, contratação e promoção dos artistas. É 0 oposto do que acontece, segundo o autor, na grande indústria do disco, em que cada etapa da produção teria sido previamente planejada, e 0 artista não possuiria nenhuma autonomia (SHUKER, 1999, p. 172) Trata-se, aqui, de uma relação de oposição entre empresas. As "independentes" operam "fora do âmbito das grandes gravadoras ou das redes nacionais de 
mídia" (VICENTE, 2006, p. 11). Mas a oposição estende-se ao universo estético, opondo músicas produzidas pela grande indústria e músicas produzidas do lado de fora dessas organizações. A distância relativa que os artistas conseguem manter do modo de operação e dos "tentáculos" das majors seria um indicativo de seu grau de "independência".

A partir desse modelo de pensamento de forte inspiração adorniana, seria possível identificar diversos níveis de "dependência", desde 0 artista completamente autônomo (como o caso do comentado LP do instrumentista e compositor Antonio Adolfo, sugestivamente intitulado Feito em Casa, lançado em 1977) até o lançamento das grandes gravadoras, inteiramente moldados segundo as necessidades comerciais (como os grupos teen Menudo, Balão Mágico, Rouge, High School Musical, entre tantos outros). Nesse sentido, é possível pensar numa gradação, onde etapas intermediárias de (in) dependência corresponderiam a produtos nos quais os artistas poderiam manter relações de colaboração e complementaridade com 0 produtor fonográfico (VAZ, 1988).

A questão da autonomia assume, assim, uma grande importância. Toda a conceituação da música independente deriva da idéia de que as grandes corporações - as "majors" - operam a partir de imposições estéticas ao artista, limitando sua liberdade criadora em benefício do mercado. Assim, a atitude independente caracteriza-se como uma peça de resistência ao poderio das multinacionais do disco, protagonizada por artistas com pouca visibilidade mercadológica. 0corre que tal atitude deixou de ser uma aventura heróica realizada por alguns agitadores culturais para se tornar uma espécie de prática produtiva de setores alijados do circuito musical hegemônico. Assim, nas últimas décadas do século XX surge no mundo inteiro um intenso movimento de "independentes" que progressivamente se institucionaliza em redes e empresas de colaboração mútua e de competição recíproca, muitas vezes desigual. Não deixa de ser irônico o fato das duas maiores gravadoras "independentes" do Brasil (Trama e Biscoito Fino), com posições de chefia na celebrada Associação Brasileira de Música Independente (ABMI), terem sido montadas e financiadas com capital especulativo de grandes grupos do sistema bancário nacional (respectivamente 0 Grupo Szajman e o Banco Icatu).

Essa configuração multifacetada do setor "independente" tem levado alguns autores a estabelecer distinções entre produção independente e produção autônoma. De acordo com Leonardo De Marchi, as produções autônomas "são caracterizadas pela ação de determinados empreendedores que tomam uma iniciativa isolada de produzir discos sem estabelecer um circuito alternativo de produção fonográfica potencialmente utilizável por outros empreendimentos" (DE MARCHI, 2005, p. 04). Nesse segmento, seria possível incluir 
os "independentes" heróicos da década de 1970 e alguns artistas propriamente marginais no mercado atual. No entanto, a música independente institucionalizada atual celebra modos de operação bastante semelhantes aos da grande indústria transnacional, apenas revestida de uma apregoada legitimidade estética, derivada de sua vinculação à noção de autonomia artística. Ser independente atualmente é simplesmente gozar de certa liberdade estética, não necessariamente dissociada do poderio financeiro das majors nem das "grandes indies". A relação entre as esferas tornou-se tão estreita que alguns autores têm apontado sua complementaridade como modo de funcionamento de todo o sistema (DIAS 2000; HERSCHMANN 2007). Além disso, é possível constatar que as ofertas musicais de muitas das chamadas independentes manifestam forte tendência de recorrer a modelos previamente consagrados, ousando pouco e reiterando a estética lançada pelas majors (DIAS, 2000, p. 130).

0 que se observa é que o panorama da circulação de música pela sociedade estabelece uma distinção entre os produtos concebidos no forno das multinacionais e os "outros", produzidos a partir de lógicas e capitais "independentes" do financiamento das "majors". Nessa distinção, opera uma forte vertente de valoração estética, agregando núcleos estilísticos radicalmente diversos a partir do compartilhamento hipotético de determinado grau de autonomia artística. Ainda que se possa argumentar que essa valoração através da autonomia seja altamente problemática e com parcas possibilidades de resistir à análise dos mecanismos de produção musical - tanto das majors quanto das "indies" trata-se de um critério valorativo-argumentativo que funciona de forma incrivelmente uniforme nos ambientes multifacetados da chamada música "independente".

Com uma reflexão instigante sobre a oposição estabelecida entre mainstream e underground, Janotti Jr. e Cardoso (2006) argumentam que tal diferenciação deriva do "grau de distanciamento entre as condições de produção e reconhecimento identificados no produto" (p. 19). Assim, produtos musicais concebidos para uma circulação massiva seriam marcados por uma distância significativa entre 0 seu ambiente de produção e de consumo, que caracterizaria sua consagração estética e comercial. Por outro lado, os produtos de circulação restrita teoricamente com maior grau de "autonomia" - seriam consagrados prioritariamente por seus pares, caracterizando uma proximidade entre produção e consumo nas estratégias de construção de legitimidade e reconhecimento. Mainstream e underground seriam, portanto, "modos diferenciados de conferir valor à música e a ideologias de audição específicas que contribuem para o sentido final da canção" (idem, p. 21). Entretanto, os autores destacam que ambos representam "estratégias de posicionamento frente ao mercado", admitindo gradações entre as esferas (idem, p. 19). De 
fato, apesar de agudas diferenças em alguns mecanismos de aferição de valor e construção de significados, a inserção quase total das iniciativas independentes no mercado musical comercial e a precária diferenciação visível (e/ou audível) em seus mecanismos de produção colocam ambas as tendências num mesmo espaço de concorrência mercadológica, reforçando a noção de complementaridade entre elas.

\section{Estratégias de mercado: a experiência}

Talvez o carnaval soteropolitano tenha sido 0 primeiro a moldar estratégias bem sucedidas de comercialização de músicas não dependentes das majors, isto é, a alavancar uma pujante cena musical altamente comercial a partir de critérios e mecanismos de produção que apontavam para um outro conjunto de etapas e modos de financiamento e circulação. A experiência do carnaval de rua movido a "trio elétrico" foi um canal de divulgação de grande alcance para difusão dos artistas da capital baiana, que, com progressivo apoio estatal, foi se nacionalizando no decorrer das décadas de 1960 e 1970, sendo absorvido com certa naturalidade ao mercado de música "oficial" durante a década de 1980.

Segundo Goli Guerreiro (2000), o encontro processado entre os "blocos de trio" (de frevo) e os blocos-afro (de "samba-reggae") no final da década de 1980 fez surgir comercialmente um dos maiores fenômenos do mainstream da música nacional: o axé music (p. 133). Numa complexa engrenagem de produção musical articulada com canais de difusão radiofônica e uma intensa identificação regional baiana, a axé music se desloca do cenário circunscrito e "independente" do carnaval de rua de Salvador para ocupar fatias significativas do mercado de música nacional, configurando-se como um dos três principais gêneros musicais do início da década de 1990 (ao lado do pagode romântico e do sertanejo, que também foram iniciados na década anterior). A receita dessa mistura pode ser substancialmente creditada à vinculação estreita com o público jovem e com a alegria contagiante do carnaval, um evento de importância crucial na configuração do que identificamos como cultura brasileira. Suas características de inversão da ordem e a dinâmica consentida de vestir "fantasias" fornecem elementos simbólicos de grande força expressiva na narração da nação.

Se no mundo diário estamos todos limitados pelo dinheiro que se ganha (ou não se ganha), pelas leis da sociedade, do mercado, da casa e da família, no carnaval e na fantasia temos a possibilidade do disfarce e da liberação. Há a possibilidade de virar onipotente e ser tudo o que se tem vontade. Ora, é precisamente por estar vivendo num mundo assim constituído, onde as regras do mundo diário estão temporariamente de cabeça para baixo, que posso ganhar e realmente sentir uma incrível sensação de liberdade (DAMATTA, 1986, p. 75).

Ao estabelecer o seu público-alvo em torno da figura do jovem, a música carnavalesca se reveste de uma série de simbologias associadas a essa faixa etária, numa época da vida em que as relações sociais festivas são propícias a altas intensidades emotivas e sexuais. Assim, a um 
evento de grande apelo corporal (festivo e erótico) e próprio para estabelecimento de estados alterados de consciência corresponde uma música de grande intensidade sonora (volumes no máximo, andamento acelerado, instrumentos e equipamentos de grande potência) que molda um ambiente de saturação característico de uma certa sensibilidade atual (CARVALHO, 1999), num conjunto de características que colocam a axé music com enorme potencial de veiculação em larga escala.

Evidentemente, a transposição de músicas de circulação restritas para 0 ambiente do mercado hegemônico é um processo natural e previsível, sendo facilmente encontráveis inúmeros exemplos em toda a história da fonografia. Esse caso ilustra muito bem a relação de complementaridade entre majors e indies, responsável pelo surgimento de vários sucessos do mercado musical durante décadas. No mesmo sentido, a música carnavalesca de Salvador é importante nesse cenário não por representar algum tipo de ruptura com um modelo de produção sedimentado pelas grandes indústrias fonográficas durante 0 século XX, mas por chamar a atenção para a força da experiência ao vivo. E também pelo fato de incorporar acentos regionais nacionalizados para determinados padrões técnicos e formais de produção musical historicamente importados do âmbito do pop-rock de língua inglesa. Isso porque a música dos trios (fundindo guitarras elétricas com 0 frevo pernambucano para a criação de um "frevo novo") e a inclinação pop das performances dos grupos de axé (associando a alegria e a dança do carnaval a um conjunto de efeitos e elementos visuais e sonoros oriundos da música dessa mesma música pop) têm como estratégia cultural assumida uma forte tendência à mistura cultural - que na modernidade brasileira seria chamada de "antropofágica" -, associando acentos regionais e nacionais a elementos característicos dessa "cultura internacionalpopular" (ORTIZ, 1988). Assim, a química entre público jovem, padrões técnicos mundializados e sotaques reconhecidamente nacionais resulta numa combinação explosiva e altamente lucrativa para 0 mercado musical, tendência que seria repetida em dezenas de outras músicas ouvidas nos últimas duas décadas.

Esse cenário não se resume geograficamente aos limites da capital baiana. Em São Luis, as radiolas de reggae se estruturam de maneira análoga, reinventando o reggae jamaicano no estado do Maranhão a partir de um poderoso mecanismo de experiência musical. Música em alto volume, dança de par, jovens e drogas (lícitas e ilícitas) estruturam um lucrativo mercado que gira em torno de "djs, magnatas e regueiros", num circuito financiado com capital privado e pessoal, notabilizado pela figura célebre do DJ e consumido em larga escala em noites de reggae por toda região metropolitana de São Luis (COSTA, 2007). 
Em Belém, a situação não difere muito. A cena musical do "brega" se estrutura a partir de polpudas "aparelhagens" que moldam um mercado musical caracterizado fortemente pela intensidade. 0 mercado musical do brega tem como eixo central a festa, predominantemente freqüentada por jovens, que buscam nesse momento de entretenimento espaço para afirmar identidades, estabelecer encontros amorosos e sexuais, além de experimentarem certa alteração de consciência.

Em todos esses exemplos, podemos destacar um eixo comum: a ênfase da circulação musical recai não na música gravada e comercializada em suportes específicos, mas sim na experiência musical ao vivo. 0 encontro sócio-musical baseado fortemente na figura do jovem e agregado a certos gêneros musicais é 0 vetor de um novo mercado regional que vai alcançar público gigantesco e fiel, configurando uma nova fatia de mercado que segue modelos próprios e que dificilmente poderia ser classificado como "independente", de acordo com o conjunto de referenciais que têm sido associados a essa classificação.

Pode-se pensar aqui em um processo de substituição parcial de um modelo fonograficocêntrico para um modelo de circulação musical voltado para a experiência, antecipando aquela que viria a ser a grande corrente de produção musical no início do século XXI.

\section{Jovem, festa, amor e sexo: o forró eletrônico}

Vamos examinar mais de perto um dos casos mais significativos do ambiente cultural que se articula em torno de novos padrões de circulação musical massiva. Contrariamente ao exemplo sazonal do axé (com exceção dos grandes artistas midiáticos que conseguem exposição durante todo 0 ano), à delimitação geográfica do reggae maranhense (que permanece como uma música local com restritas possibilidades de nacionalização) ou mesmo ao comentado brega do Pará (ainda que a cena brega tenha se espalhado por diversos estados do Nordeste, seu pólo irradiador ainda está estreitamente vinculado à cidade de Belém), o caso do "forró eletrônico" representa uma espécie de síntese do processo de construção de um novo mainstream, não mais vinculado aos corredores das multinacionais do disco nem aos grandes conglomerados de mídia nacionais e internacionais.

0 mercado alternativo do forró foi inaugurado no início dos anos 1990 pela banda cearense Mastruz com Leite, organizada pelo empresário Emanoel Gurgel, que pretendia revolucionar os padrões do gênero, tornando-o "estilizado e progressista". Para atingir o objetivo, o empresário montou um poderoso sistema de rádios via satélite que dava suporte à divulgação de seus produtos musicais, a Somzoom Sat. Tem-se aqui uma primeira diferenciação entre os padrões vigentes da 
indústria fonográfica. Ao invés de organizar um empreendimento cultural baseado na aquisição de equipamentos e licenças de comercialização e/ou difusão, Gurgel "monta" uma banda e passa a agenciar shows pelo Nordeste, veiculando músicas de seus artistas através de sua rádio. Deve-se mencionar que a Somzoom não é uma emissora de rádio no sentido específico do termo, pois não tem concessão para transmitir o sinal e ocupar uma faixa do espectro radiofônico, sendo exclusivamente uma geradora de conteúdo para suas afiliadas. Assim, o empresário conseguiu articular uma competente estrutura comercial para sua banda e sedimentou o sucesso de sua estação de rádio, que em pouco tempo passou a transmitir seu conteúdo via satélite para dezenas de afiliadas em todo o Nordeste. 0 sucesso da Mastruz repercutiu nas ondas das rádios da Somzoom, formando em pouco tempo um significativo mercado para o novo forró que vinha do Ceará. Sob a batuta de Gurgel, além da Mastruz formaram-se outras dezenas de bandas de perfil semelhante, divulgadas durante a década de 1990 pela rádio. Atuando ainda como gravadora, a Somzoom foi (e ainda é) a principal responsável pela divulgação de novas e consagradas bandas de forró eletrônico (PEDROZA, 2001, p. 2), como Limão com Mel, Caviar com Rapadura, Aviões do Forró, Calcinha Preta e Saia Rodada. No mercado atual do forró eletrônico, as bandas são "propriedade" de empresários do ramo do entretenimento (agregados em "produtoras culturais") que com freqüência agregam atividades de gerenciamento de várias bandas (incluindo agenda, gravações, comercialização e venda de shows), casas de shows, assessoria de imprensa e toda a estrutura comercial que gira em torno do mercado de shows.

Contudo, o que mais impressiona no sucesso desse segmento montado inicialmente por Gurgel não é tanto a sua sofisticada estrutura comercial baseada em moldes alternativos aos praticados pelo mercado musical nacional até então. Na verdade, o sucesso da Mastruz (hoje com reduzida participação no mercado, mas reconhecida como precursora de uma determinada tendência estética) e das atuais Aviões, Calcinha Preta e Saia Rodada, entre dezenas de outras, é o seu conteúdo. Endereçada predominantemente para um público jovem de diversas cidades dos nove estados nordestinos (e além da região), a música do forró eletrônico traz uma característica fundamental para sua projeção comercial: uma explícita apologia da festa como lugar de realização social e, sobretudo, amorosa e sexual. 0 trinômio festaamor-sexo funciona como um elo fundamental de atração e sedução de grande contingente de jovens para o contexto da experiência social da música. 0 show é 0 evento central nesse processo e todas as etapas da produção musical apontam para esse momento de festa, onde as simbologias serão compartilhadas através do repertório musical. Assim, dança, festa, desilusões amorosas, encontros sexuais (tanto aqueles 
ocorridos no interior de uma relação de um casal consolidado quanto os intencionalmente voláteis e eminentemente físicos, sem nenhum grau de afetividade) e bebida formam um conjunto de temáticas que constroem 0 ambiente afetivo do forró eletrônico endereçado aos jovens em festa.

Possivelmente, essa "receita" de sucesso represente um modelo alternativo de construção de uma identidade nordestina (o termo forró referencia uma série de simbologias associadas à construção imaginária da região) tencionada pelas influências da cultura internacionalpopular. Parece relevante, porém, destacar que as estratégias comerciais vinculadas à comercialização de shows encontram nesse universo simbólico de temáticas musicais uma coerência de grande força expressiva, moldando um ambiente cultural de alcance massivo e de aguda penetração social.

0 sistema comercial que gira em torno do forró eletrônico está abertamente adequado ao momento tecnológico de perda de valor da música gravada e de maior significação simbólica e financeira da experiência musical ao vivo. No entanto, pode-se levantar aqui as contradições de tal estruturação no que diz respeito à autonomia artística. Tomada como critério de distinção entre majors e indies, ao lado de uma vaga noção de independência do capital transnacional, a idéia de autonomia estética parece totalmente irrelevante para os artistas e produtores do segmento do forró eletrônico. A relação adotada por esses agentes para com sua produção musical aponta para um certo utilitarismo da música no qual a forma é inteiramente sobrepujada por sua funçã $0^{3}$. Assim, é suficiente ter um conjunto de canções capazes de articular valores voltados para o próprio evento (a festa) através de uma estratégia de sedução que toca em pontos bastante sensíveis da afetividade jovem (amor e sexo). A combinação explosiva das três variáveis é moldada (o termo um tanto apocalíptico parece irremediavelmente apropriado) como uma estratégia comercial e estética na qual a margem de manobra criativa e inovadora é ínfima. Levanta-se aqui, em segundo plano, uma segunda questão relacionada aos critérios de qualidade da música popular, que, neste caso, parecem fadados a serem revistos a partir do redimensionamento valorativo entre autonomia e padronização.

Por todas essas razões, a caracterização do ambiente do forró eletrônico como música independente parece inadequada. Apesar de sua estrutura comercial prescindir do apoio do capital dos grandes conglomerados transnacionais de entretenimento, seu intencional afastamento dos critérios de autonomia artística e independência estilística colocam essa produção numa zona ambígua 
de classificação estética. Por outro lado, sua gigantesca projeção em eventos, feiras, festas e shows de grande porte em todas as cidades das regiões Norte e Nordeste (além de sua robusta divulgação radiofônica) colocam 0 forró eletrônico como uma música regional compartilhada em larga escala, seguindo modelos e quantitativos análogos aos do mainstream das multinacionais do disco.

\section{Um novo mainstream}

0 mercado de música atual tem se transformado em uma arena de calorosos debates e muitas incertezas. As previsões mais otimistas apontam as novas tecnologias como vetores de uma possível "democratização" da oferta de música disponível, representando uma perda de importância dos grandes conglomerados do entretenimento internacional no cenário. Trata-se de uma utopia um tanto ingênua, que indica certo deslumbramento com as reais possibilidades da atual configuração tecnológica em diversificar o consumo de música. É evidente que se observa a emergência de canais alternativos de circulação musical que, de fato, têm provocado algum aumento da diversificação de ofertas musicais. Contudo, uma comemoração mais entusiasmada dessas novas redes de distribuição e circulação de música pode ser precipitada, uma vez que a grande maioria da produção e consumo de músicas pelo planeta ainda passa irremediavelmente pelo controle das grandes gravadoras, que estão desenvolvendo mecanismos empresariais e técnicos para manter sua (sempre alta) lucratividade. Do outro lado, o discurso atemorizado dessa grande mídia sobre suas perdas deve ser relativizado, uma vez que 0 tom assombrado que percorre essas declarações não encontra explicação lógica ou evidência quantitativa que o sustente. As grandes empresas continuam controlando o mercado no seu setor mais oneroso: a difusão, que movimenta gastos consideráveis para o lucro direto advindo de cada disco, de cada show, de cada artista.

Entre os assombrados e os deslumbrados, no entanto, pode-se identificar um mercado em transformação que permite poucas certezas e quase nenhum tipo de previsão futurística. É fato que uma compreensão mais aprofundada desse universo amplo e complexo não pode mais se associar exclusivamente a uma diferenciação utópica entre independentes e mainstream. Por outro lado, as gradações de alcance entre os vários produtos disponíveis no mercado musical nos encorajam a adotar os dois pólos como norteadores de referências simbólicas e quantitativas sobre a música que circula por nossa sociedade. Nesse sentido, algumas mudanças no âmbito do grande mercado podem ser identificadas sem grande esforço, agregando um conjunto de práticas musicais com inquestionável sucesso comercial que vêm desenvolvendo mecanismos alternativos aos adotados pelas grandes transnacionais da música e do entretenimento. "Alternativo" aqui não significa "contra-hegemônico" no conceito 
gransciniano, mas simplesmente um jeito

diferente de fazer o mesmo, alcançando projeção

midiática e público numeroso. A substancial redução da autonomia artística promovida pelos "escritórios" (para usar um termo de Adorno e Horkheimer, 1982) que controlam as bandas de forró (assim como os "produtores" dos trios elétricos baianos, os "donos" das aparelhagens de brega e os "magnatas" do reggae) produz um agudo afastamento ideológico entre as condições de produção efetivamente empregadas nesses mercados e as noções - um tanto românticas de independência artística que alimentam um sentido propriamente de resistência das chamadas "indies". Assim, a caracterização desse universo sonoro musical como um novo mainstream pode colocar essa produção e seu consumo num contexto de reflexão mais adequado ao seu alcance numérico e ao conjunto de referenciais simbólicos que circulam através desses repertórios. Um novo mainstream ligado à exploração comercial da experiência musical social, promovida especialmente para um público jovem que deseja compartilhar representações sobre sua identidade etária através das idéias concomitantes de festa, amor e sexo, temas centrais no ambiente sociocultural e afetivo do jovem.

\section{Referências bibliográficas}

ADORNO, T. \& HORKHEIMER, M. A industria cultural: o Iluminismo como mistificação de massas In: LIMA, Luiz Costa (org.). Teoria da cultura de massa. Tradução: Júlia Eliabeth Levy. Rio de Janeiro, Paz e Terra, 1982.
ANDERSON, Chris. A cauda longa: do mercado de massa para o mercado de nicho. Rio de Janeiro: Elsevier, 2006.

BOURDIEU, Pierre. 0 poder simbólico. Rio de Janeiro: Bertrand Brasil, 1989.

A distinção: crítica social do julgamento.

Porto Alegre: Zouk; São Paulo: Edusp, 2007.

CARVALHO, José Jorge de. Transformações na sensibilidade musical contemporânea. Série

Antropologia, n. 266. Brasília: UnB, 1999.

COSTA, Rogério. Djs, magnatas e regueiros: considerações sobre o reggae de São Luis. In: ENCONTRO DE MÍDIA E MÚSICA POPULAR MASSIVA. 1., 2007, Salvador (mimeo) Salvador: Edufba, 2007.

DAMATTA, Roberto. 0 que faz o brasil, Brasil? Rio de Janeiro: Rocco, 1986.

DE MARCHI, Leonardo. "Indústria fonográfica independente brasileira: debatendo um conceito". In: Anais do XXVIII CONGRESSO BRASILEIRO DE CIÊNCIAS DA COMUNICAÇÃO, 2005. Rio de Janeiro: Intercom, 2005. CD-ROM.

DIAS, Márcia Tosta. Os donos da voz: indústria fonográfica brasileira e mundialização da cultura. São Paulo: Boitempo; FAPESP, 2000.

GUERREIR0, Goli. A trama dos tambores: a música afro-Pop de Salvador. São Paulo: 34, 2000.

HERSCHMANN, Micael. Lapa, cidade da música. Rio de Janeiro: Mauad X, 2007.

JANOTTI Jr., Jeder; CARDOSO FILHO, Jorge. A música popular massiva, o mainstream e o underground". In: JANOTTI JR.., Jeder ; FREIRE FILHO, João (orgs.). Comunicação \& Música Popular Massiva. Salvador: EdUFBA, 2006.

ORTIZ, Renato. A moderna tradição brasileira. São Paulo: Brasiliense, 1988. 
PEDR0ZA, Ciro José Peixoto. Mastruz com Leite for all: folk-comunicação ou uma nova indústria no Nordeste brasileiro. In: Anais do XXIV CONGRESSO BRASILEIRO DE CIÊNCIAS DA COMUNICAÇÃO, 2001. Campo Grande: Intercom, 2001. CD-ROM.

SHUNKER, Roy. Vocabulário de música pop. São Paulo: Hedra, 1999.

TROTTA, Felipe. 0 forró de Aviões. In: ENCONTRO ANUAL DA COMPÓS, 17., 2008. Anais... São Paulo : Compós, 2008, v. 1, p. 1-13.

VAZ, Gil Nuno. História da música independente. São Paulo: Brasiliense, 1988.

VICENTE, Eduardo. A vez dos independentes(?): um olhar sobre a produção musical independente do país. E-Compós, v. 7, p. 1/19-19/19, Brasília, 2006. 
The new mainstream in regional music: axé, brega, reggae and Electronic forró electrónico in the Northeast.

\section{Abstract}

This papers intends to locate part of the Brazilian Northeast musical production as held inside of the mainstream of the regional music market. These musical practises - axé, brega reggae and forró - are highly spread in society, getting to a level of consumption that exceeds the limits of the classification "independent". So, these musical universes articulate some sets of values and symbols addressed explicitly to the young and associated to the ideas of party-love-sex, with great commercial success.

\section{Keywords}

Music market. Popular music. Forró. Indies.

\section{El nuevo mainstream de la música regional: axé, brega, reggae y forró electrónico en el Nordeste.}

\section{Resumen}

Comenzando con una reflexión sobre el concepto de música independiente, este artículo tiene por objeto caracterizar la producción musical del Nordeste brasileño como un nuevo mainstream regional. Con el expresiva circulación en la región, la música de algunos géneros tales como axé, brega, reggae y el forró electrónico llega a una consagración comercial que excede los límites de la clasificación indepiendente. Por lo tanto, en estas prácticas musicales se puede observar una serie de valores y símbolos asociados con el público joven que, girando en torno a las ideas del fiesta-sexo-amor, alcanzan la gran proyección en el mercado musical.

\section{Palabras clave}

Mercado musical. Música popular. Forró. Independientes. 


\section{Expediente}

A revista E-Compós é a publicação científica em formato eletrônico da Associação Nacional dos Programas de Pós-Graduação em Comunicação (Compós). Lançada em 2004, tem como principal finalidade difundir a produção acadêmica de pesquisadores da área de Comunicação, inseridos em instituições do Brasil e do exterior.
E-COMPÓS I www.e-compos.org.br I E-ISSN 1808-2599

Revista da Associação Nacional dos Programas de Pós-Graduação em Comunicação. Brasília, v.11, n.2, maio/ago. 2008

A identificação das edições, a partir de 2008 passa a ser volume anual com três números.

\section{CONSELHO EDITORIAL}

\section{Afonso Albuquerque}

Universidade Federal Fluminense, Brasil

Alberto Carlos Augusto Klein

Universidade Estadual de Londrina, Brasi

Alex Fernando Teixeira Primo

Universidade Federal do Rio Grande do Sul, Brasi

Alfredo Vizeu

Universidade Federal de Pernambuco, Brasil

Ana Carolina Damboriarena Escosteguy

Pontifícia Universidade Católica do Rio Grande do Sul, Brasil

Ana Silvia Lopes Davi Médola

Universidade Estadual Paulista, Brasil

André Luiz Martins Lemos

Universidade Federal da Bahia, Brasil

Ângela Freire Prysthon

Universidade Federal de Pernambuco, Brasil

Antônio Fausto Neto

Universidade do Vale do Rio dos Sinos, Brasil

Antonio Carlos Hohlfeldt

Pontifícia Universidade Católica do Rio Grande do Sul, Brasil

Arlindo Ribeiro Machado

Universidade de São Paulo, Brasil

César Geraldo Guimarães

Universidade Federal de Minas Gerais, Brasi

Cristiane Freitas Gutfreind

Pontifícia Universidade Católica do Rio Grande do Sul, Brasil

Denilson Lopes

Universidade Federal do Rio de Janeiro, Brasil

Eduardo Peñuela Cañizal

Universidade Paulista, Brasil

Erick Felinto de Oliveira

Universidade do Estado do Rio de Janeiro, Brasil

Francisco Menezes Martins

Universidade Tuiuti do Paraná, Brasil

Gelson Santana

Universidade Anhembi/Morumbi, Brasil

Hector Ospina

Universidad de Manizales, Colômbia

leda Tucherman

Universidade Federal do Rio de Janeiro, Brasil

Itania Maria Mota Gomes

Universidade Federal da Bahia, Brasil

Janice Caiafa

Universidade Federal do Rio de Janeiro, Brasil

Jeder Silveira Janotti Junior

Universidade Federal da Bahia, Brasil
John DH Downing

University of Texas at Austin, Estados Unidos

José Luiz Aidar Prado

Pontifícia Universidade Católica de São Paulo, Brasil

José Luiz Warren Jardim Gomes Braga

Universidade do Vale do Rio dos Sinos, Brasi

Juremir Machado da Silva

Pontifícia Universidade Católica do Rio Grande do Sul, Brasil

Lorraine Leu

University of Bristol, Grã-Bretanha

Luiz Claudio Martino

Universidade de Brasília, Brasil

Maria Immacolata Vassallo de Lopes

Universidade de São Paulo, Brasil

Maria Lucia Santaella

Pontifícia Universidade Católica de São Paulo, Brasil

Mauro Pereira Porto

Tulane University, Estados Unidos

Muniz Sodre de Araujo Cabral

Universidade Federal do Rio de Janeiro, Brasil

Nilda Aparecida Jacks

Universidade Federal do Rio Grande do Sul, Brasil

Paulo Roberto Gibaldi Vaz

Universidade Federal do Rio de Janeiro, Brasil

Renato Cordeiro Gomes

Pontifícia Universidade Católica do Rio de Janeiro, Brasil

Ronaldo George Helal

Universidade do Estado do Rio de Janeiro, Brasil

Rosana de Lima Soares

Universidade de São Paulo, Brasil

Rossana Reguillo

Instituto Tecnológico y de Estudios Superiores do Occidente, México

Rousiley Celi Moreira Maia

Universidade Federal de Minas Gerais, Brasil

Sebastião Carlos de Morais Squirra

Universidade Metodista de São Paulo, Brasil

Simone Maria Andrade Pereira de Sá

Universidade Federal Fluminense, Brasil

Suzete Venturelli

Universidade de Brasília, Brasil

Valério Cruz Brittos

Universidade do Vale do Rio dos Sinos, Brasil

Veneza Mayora Ronsini

Universidade Federal de Santa Maria, Brasil

Vera Regina Veiga França

Universidade Federal de Minas Gerais, Brasil

\section{COMISSÃO EDITORIAL}

Ana Gruszynski I Universidade Federal do Rio Grande do Sul, Brasil João Freire Filho I Universidade Federal do Rio de Janeiro, Brasil Rose Melo Rocha I Escola Superior de Propaganda e Marketing, Brasil

\section{CONSULTORES AD HOC}

Aníbal Bragança I Universidade Federal Fluminense, Brasil Gisela Castro I Escola Superior de Propaganda e Marketing, Brasil

Gislene Silva I Universidade Federal de Santa Catarina, Brasil

Maria Helena Weber I Universidade Federal do Rio Grande do Sul, Brasil

Rosana de Lima Soares I Universidade de São Paulo, Brasil

Tania Hoff I Escola Superior de Propaganda e Marketing, Brasil

REVISÃO DE TEXTO E TRADUÇÃo I Everton Cardoso

ASSISTÊNCIA EDITORIAL E EDITORAÇÃO ELETRÔNICA I Raquel Castedo
COMPóS I www.compos.org.br

Associação Nacional dos Programas de Pós-Graduação em Comunicação

Presidente

Erick Felinto de Oliveira

Universidade do Estado do Rio de Janeiro, Brasil erickfelinto@uol.com.br

Vice-presidente

Ana Silvia Lopes Davi Médola

Universidade Estadual Paulista, Brasil

asilvia@faac.unesp.br

Secretária-Geral

Denize Correa Araújo

Universidade Tuiuti do Paraná, Brasil

denizearaujo@hotmail.com 